\title{
"Lo que es sagrado se baila": una aproximación a la ontología Xavante desde el análisis de cuatro danzas involucradas en el ritual de iniciación de los adolescentes ${ }^{1}$
}

\author{
Massiel Román Molero \\ Estudiante de Filosofía en la Pontificia Universidad Católica del Perú (PUCP). \\ Miembro del Círculo de estudios japoneses Tenjin. \\ e-mail: massiel.roman@pucp.edu.pe
}

\section{Resumen}

A partir del análisis de cuatro danzas, este trabajo tiene como intención realizar una primera aproximación y reflexionar ante la siguiente pregunta: ¿de qué manera las danzas involucradas en el ritual de iniciación $-\mathrm{y}$ con ellas, su experiencia como cuerpo danzante- del Wapté-Xavante lo forman ontológicamente? La hipótesis que sostenemos es que en las danzas se expresa la transformación ontológica que ha de vivir el muchacho en la iniciación. En esta ontología se desarrollan capacidades: la capacidad de lidiar con el propio peso corporal e integrar lo ligero/pesado en su propio movimiento; la capacidad de repetir $\mathrm{y}$, con ello, ser capaz de moverse entre los polos de diferenciación e identidad; las capacidades de escuchar, pensar, observar y recordar los sueños; y la capacidad de cohesionarse afectivamente a su grupo de edad. Pero estas características ontológicas se alcanzan a partir de la experiencia de los límites y del sufrimiento; dicho sea, a través de los límites es que el Xavante se hace una persona plena.

\section{Palabras clave}

Perspectivismo amerindio, danza, ontología, Xavante, corporalidad, filosofía de la danza.

\footnotetext{
1 Quisiera agradecer los valiosos comentarios de los revisores anónimos del escrito, del Comité Editorial de la revista Anthropía y, finalmente, de Josefina Rodríguez, quien leyó una versión previa de este artículo, por sus sugerencias y soporte incondicional. Nota editorial: el presente artículo fue recibido el 11-03-2021 y aprobado el 14-03-2021.
} 


\title{
"What is sacred is danced": an approach to the Xavante ontology from an analysis of four dances involved in the adolescent's initiation ritual
}

\author{
Massiel Román Molero \\ Philosophy student at the Pontifical Catholic University of Peru (PUCP). \\ Member of the Circle of Japanese Studies Tenjin. \\ e-mail: massiel.roman@pucp.edu.pe
}

\begin{abstract}
Based on the analysis of four dances, this work intends to make a first approach and reflect on the following question: in what way the dances involved in the initiation ritual -and with them, their experience as a dancing body- of the WaptéXavante form it ontologically? The hypothesis that we maintain is that in these dances the ontological transformation that the boy has to experience is expressed. In this ontology, some capacities are developed: the ability to deal with one's own body weight and integrate the dialectic between light and heavy into one's own movement; the ability to repeat and, with it, to be able to move between the poles of differentiation and identity; the abilities to listen, think, observe and remember dreams; and the ability to bond emotionally to his age group. But these ontological characteristics are reached because of the experience of limits and suffering; In other words, it is through the limits that the Xavante becomes a full person.
\end{abstract}

\section{Keywords}

Amerindian perspectivism, dance, ontology, Xavante, corporality, philosophy of dance. 


\section{Introducción}

En El mito del eterno retorno, Mircea Eliade señala que los rituales humanos poseen un modelo divino arquetípico. Su ejecución se realiza en tanto aquello que se repite es una acción llevada a cabo por un antepasado, un héroe, o un dios en el mito (2000). La acción a replicar enseñará la manera en que debe llevarse a cabo la repetición y, a su vez, a través de dicha práctica se verá acentuada la dependencia -a juicio del autor-causal entre el ámbito de lo sagrado y lo humano, en tanto es por el primero que este último obtiene su realidad. Una de las formas más usuales de dicha acción ha tenido expresión en las danzas. Con todo, debe notarse que la actividad dancística no se limita a ser exclusivamente una "repetición" de aquella acción primigenia porque, de hecho, la danza nos dice -y se dice a sí misma- mucho más. Juan Subirá traduce en palabras aquello a lo que apuntarán, en líneas generales, los estudios dancísticos de Kurath y von Laban en el siglo XX, así como el interés creciente por dicha disciplina en los años 1950/1970 (Citro, 2012): existen cosas que solo se dicen y se plasman danzando. Por consiguiente, hay formas dancísticas de pensar-nos.

Este trabajo, en particular, tiene como objeto de estudio algunas de las danzas involucradas en el ritual de iniciación del joven Xavante. Antes de continuar con este punto, es crucial conocer un poco más sobre los $A$ 'uwẽ-Xavante. Los Xavante residen en más de 200 comunidades autónomas en el estado de Mato Grosso, Brasil, su lengua es parte de la familia lingüística Gê y son conocidos en la antropología social por sus complejos e interseccionales sistemas de organización dual ${ }^{1}$ (Graham, 2019). Detengámonos aquí brevemente. Según Graham (2019), la sociedad Xavante se compone de múltiples sistemas duales/binarios transversales. De hecho, Welch (2010) identifica hasta cinco tipos de sistema de mitades (moieties): los grupos de edad seculares y espirituales, los Wood-Owners (wedehöri'wa)-que apelan a un espíritu benevolente- y los Rattle-Owners (umrê'tede'wa)-que, en contraposición, apelan a un espíritu "malévolo"-, las mitades patriliniales, poreza'õno y öwawe, y la división física de la villa o comunidad entre izquierda (danhimi'e) y derecha (danhimire), lo cual sirve para distribuir la comida y los bienes entre las personas. En este trabajo, nosotros nos enfocaremos solamente en los grupos de edad seculares, los cuales, para los Xavante, se denominan en una de las mitades Ai'rere, Tirowa, Abare'u, Aanarowa y, en otra de las mitades Hötöra, Etêpa, Nodzö'u, Isada'ro (Graham, 1995). De esta manera, como señalan Franco y Huertas (2018), en esta sociedad existen divisiones etarias organizadas de forma jerárquica, de tal manera que cada mitad tiene cuatro conjuntos de edades ordenadas jerárquicamente. Asimismo, "solo los hombres poseen un conjunto binario adicional dentro del complejo Wai'a que cruza aun más las mitades agámas y exógamas" (Graham, 2019, p. 214). Por ende, un individuo puede pertenecer a las mitades pö'redza'ōnō

1 La traducción es nuestra. En adelante, las citas de textos en inglés y portugués serán traducidas también al español. 
y owawe en virtud de su descendencia patrilineal y, en adición, a uno de los conjuntos de las ocho edades dentro de las mitades (por ejemplo, ser un Hötöra). Debe notarse, finalmente, dos cosas: en primer lugar, los niños se asignan a una de las dos mitades de acuerdo con sus atributos físicos y "espirituales"; $y$, en segundo lugar, la organización interna de cada clase de edad reside en que estos jóvenes hayan iniciado juntos el periodo previo al rito de paso en la $H \ddot{o}$, como veremos más adelante, conocida también como la casa de los solteros.

A nuestro juicio, Graham apunta de forma importante que "Varias actividades, incluyendo prácticas expresivas tales como la canción y la danza, dando vida y lazos afectivos entre los miembros de los grupos" (2019, p. 214). En esa línea, nos preguntamos si la importancia de la danza en particular no solo se refleja en los lazos entre los miembros de dichos conjuntos, sino también en la manera en que estos mismos se constituyen ${ }^{2}$. Es así que la interrogante a partir de la cual este trabajo busca aproximarse al tema es la siguiente: ¿de qué manera las danzas de iniciación -y con ellas, su experiencia como cuerpo danzante- del WaptéXavante lo forman ontológicamente como individuo? La hipótesis que sostenemos es que en las danzas se expresa la transformación ontológica que ha de vivir el muchacho que ha de iniciarse. En esta ontología se desarrollan capacidades: la capacidad de lidiar con el propio peso corporal e integrar lo ligero/pesado en su propio movimiento; la capacidad de repetir y, con ello, ser capaz de moverse entre los polos de diferenciación e identidad; las capacidades de escuchar, pensar, observar y recordar los sueños; y la capacidad de cohesionarse afectivamente a su grupo de edad. Pero estas características ontológicas se alcanzan a partir de la experiencia de los límites y del sufrimiento; dicho sea, a través de los límites es que el Xavante se hace una persona plena. Para sostener esta hipótesis nos referiremos, a continuación, al marco teórico en cuestión; seguidamente, nos detendremos en la metodología y división del análisis; y, posteriormente, pasaremos al análisis de las danzas escogidas.

\section{El marco teórico y la metodología}

Los conceptos a utilizar en este trabajo se sitúan dentro de la corriente del perspectivismo amerindio. El trabajo del que partimos es el desarrollado por Viveiros de Castro. En términos generales, dicho autor propone que el punto de vista crea al sujeto -este último puede ser tanto humano como no-humano-. La forma general que tomará el sujeto será dada por el nombre "humanidad". Sin embargo, ello no significa que los animales sean sujetos porque son humanos, sino que son "humanos" porque son sujetos potenciales (2015). La forma en que se ven a sí mismos, por tanto, los no-humanos como los animales, es como humanos. Con todo, debemos

\footnotetext{
2 Reconocemos, ciertamente, la relevancia de los cantos y lo sonoro en la ceremonia de iniciación Xavante, pero, debido al espacio que ello ocuparía, nos concentraremos en el análisis de la danza. Sin embargo, nos referiremos a ambos puntos cuando consideremos necesario.
} 
notar que "humano" no significa Homo sapiens, sino que refiere a la "condición social del ser persona (personhood)" (Viveiros de Castro, 2015, p. 242). A partir de este enfoque, lo que tendremos en cuenta en adelante es que, en apariencia, lidiamos con una multiplicidad de ontologías y una epistemología amerindia. Una manera en que se estructura la realidad es a través de la división formal entre cultura, naturaleza y supernaturaleza. Veamos brevemente esto a continuación.

Viveiros de Castro propone una definición de cultura como la naturaleza del sujeto en la que "cultura" sería el esquema autoantropológico de los pronombres en primera persona "I" o "me" (2015, p. 250). Ahora bien, si tanto los humanos como los nohumanos se refieren a sí mismos como "humanos", ¿cuál es el suelo compartido que permite la autorreferencialidad en estos términos? Este suelo es el alma. Es aquello que nos permite ser sujetos y tener un punto de vista, pero, ya que es idénticamente formal en todas las especies -es decir, todos tenemos alma- y, por tanto, solo puede ver las mismas cosas en todos lados, no puede ser el principio de diferenciación de dichos puntos de vista. Aquello que lo permite se halla en el ámbito de la naturaleza: el cuerpo. Con ello no nos referimos a la fisiología corporal, sino a los afectos, en el antiguo sentido de disposiciones o capacidades que hacen único el cuerpo de cada especie: qué come, cómo se mueve, cómo se comunica, dónde vive, o si es gregario o solitario (2015). En otras palabras, se ve al cuerpo simultáneamente como sede de pathémata y dýnamis, lo cual sugiere que la sustancialidad y plenitud (y, a la inversa, incompletitud) se construye a través de las formas de ser o la manera en que se vivan lo que le afecta. El cuerpo es la manera en que la alteridad se aprehende. Si la "cultura" es la perspectiva reflexiva del sujeto, la "naturaleza" es el punto de vista que el sujeto toma sobre el otro en tanto cuerpo, esto es, el objeto para un sujeto (2015, p. 258). Es preciso apuntar sobre el cuerpo que, ya que permite la alteridad entre perspectivas, para afirmarse en la identidad será importante diferenciarlo lo más que se pueda para expresarlo. Al parecer, la semiótica será el correlato necesario de un proceso interior que lleva a cabo un individuo respecto a la comunidad de valores en la que se halla inserto: la construcción social del cuerpo permite los vínculos sociales (Martinez, 2007). En esa línea, las palabras de un anciano Xavante respecto a la filmación de la ceremonia de iniciación son emblemáticas: "Entiendo la importancia de la imagen, por eso deben aprender a filmar, para que los Xavantes puedan grabar sus ceremonias. Sabíamos que ustedes vendrían a filmar, todos se pusieron contentos. ¡Sean bienvenidos!” (Tserewahú, 1999, 04m26s).

Así, aquello que permita diferenciar la identidad será, por tanto, de sumo cuidado; de ahí la importancia de la construcción del cuerpo, su decoración y lo que tiene contacto con él (como, por ejemplo, la comida). Finalmente, respecto al ámbito de la supernaturaleza, aunque no sea posible entrar en mayor detalle, sí quisiéramos apuntar hacia un proceso importante en juego: la metamorfosis. Esta última será un intercambio de perspectivas relacional característico de estas ontologías. Con el cambio de perspectivas cambia el mundo: en las danzas, los danzantes enmascarados se transforman realmente en los seres representados. Como sucede con los Wauja 
(Barcelos, 2006), la transformación se da a través de instrumentos como las ropas o la intervención de seres intermedios como los chamanes.

Ahora bien, una de las maneras en las que el cuerpo aprehende su propia alteridad tiene lugar en el ritual. Para aproximarnos a este, es importante que mencionemos brevemente aquella tensión entre el pensamiento y la acción que, a juicio de Catherine Bell (2009), es constitutiva de la forma en que se ha intentado definir el ritual, lo cual puede ser visto en tres niveles: (i) una tendencia consiste en analogar al ritual a la acción y diferenciarlo del pensamiento; (ii) otra remite a la concepción del ritual como mecanismo estructural para integrar el pensamiento y la acción; y finalmente (iii) existe un enfoque que da cuenta del ritual como instancia en la que se integra nuestro pensamiento (como observadores) y su acción (esto es, la acción de los participantes del ritual). Insistir en solo uno de estos aspectos del ritual puede tener algunos problemas como el que se aisle el ritual del complejo contexto en el que se halla al entenderlo solamente como práctica mientras se corre el riesgo, además, de concebirlo como acciones rutinarias y meramente físicas, las cuales serían una consecuencia secundaria del pensamiento; se conciba al ritual como aquel mecanismo a través del cual debieran simplemente solucionarse las contradicciones entre el pensamiento y la acción en el tejido social; y se tenga como presupuesto que el "significado" del ritual pueda ser plenamente accesible para una lectura cuidadosa de quien lo estudie, lo cual puede restar importancia a las mismas acciones llevadas a cabo en él. Puede pensarse que algo común a cada una de estas tendencias aisladas es que abstraen el contenido del ritual de la misma vivencia de este en el contexto propio de los participantes o actores, esto es, lo vacían. Aunque ciertamente no nos es posible entrar en una discusión mayor al respecto, consideramos que el enfoque del ritual por el que aboguemos debe tender a integrar estos tres aspectos, así como procurar el esfuerzo por escuchar y hacer central la perspectiva de quienes están viviendo esa precisa instancia en sus propios términos. De tal modo, pareciera inevitable considerar al "ritual" como un concepto clasificatorio de segundo orden que, siguiendo a Bell (2009, p. 54), sería "un dispositivo eminentemente adecuado para la organización de una conversación teórica que desee desconvertir significados culturales a través de la interpretación de «textos» que «huelen a significado»". A través de este "dispositivo" se distingue y privilegia una distinción cualitativa entre lo sagrado y lo profano, y puede adscribirse esta distinción a realidades que trasciendan las facultades de los actores humanos. Según la autora, cuatro son las características del ritual como actividad humana (2009, pp. 81-85): (a) es situacional, esto es, mucho de lo que es importante para él no puede ser aprehendido más allá del contexto específico en el que ocurre; (b) es estratégico, esto es, tiene una lógica económica y práctica que le permita cumplir su objetivo; (c) hay una una falta de reconocimiento fundamental (o "fundamental 'misrecognition"”) de los límites de lo que se hace, esto es, a los ojos del observador, la práctica está llena de ambigüedades y no reconoce los límites y restricciones posibles a la acción dentro de un contexto fuera del ritual; $\mathrm{y}$ (d) contiene una serie de concepciones o ideas sobre la distribución de las relaciones de poder entre los involucrados. 
Como fue planteado inicialmente, para aproximarnos a la danza, nuestra intención es enfocarnos en un tipo de ritual, los llamados "rites de passage"3. Según Van Gennep, los ritos de transición son aquellos que acompañan todo cambio de lugar, estado, posición social y edad. Estos ritos se descomponen en (i) ritos de separación del mundo anterior-o preliminares-, (ii) ritos ejecutados durante el "margen" -o liminares- y (iii) ritos de agregación al mundo nuevo o posritual -o posliminares- $(2008$, p. 38). Para esta clasificación es fundamental el concepto de margen, pues da cuenta de "un tiempo más o menos prolongado, en una situación especial" (2008, p. 34) en la que el neófito flota entre dos mundos, el anterior y el posterior al ritual. El margen es una marca, una zona neutra que señala el paso de una realidad a otra. Siguiendo esta clasificación, es de nuestro interés tomar en consideración dos conceptos que plantea Turner (1988): la liminalidad y la communitas. Frente al tratamiento de Van Gennep, el limen es elaborado por Turner con mayor detalle. Bajo su mirada, es visto como un periodo en el que los atributos de las personas liminales son necesariamente ambiguos, pues en dicha condición los sistemas de clasificaciones que establecen posiciones sociales no aplican. En la zona "neutra", sus atributos indeterminados se expresan por medio de una gran variedad de símbolos; por ejemplo, pueden representarse como seres desposeídos, andar desnudos, con un taparrabos, o con algún signo visible que muestre que "en cuanto seres liminales que son, no tienen status, propiedades, distintivos, vestimenta secular que indique el rango o rol, ni posición alguna dentro de un sistema de parentesco" $(1988$, p. 102). De cierta manera, podría decirse que los neófitos se equiparan todos a un estado similar en el que no existe diferencia tangible entre ellos, tal como si fueran un cuerpo que será formado y provisto de distintas capacidades y cualidades en pos de la nueva realidad a la que se integrarán. Más aún, podría pensarse que la liminalidad es el requisito para que el neófito posea una nueva constitución ontológica. La liminalidad implica, por su parte, que el paso de una posición inferior se da a través de un umbral carente de status. Esto es lo que justamente nos lleva al segundo punto, la communitas. Turner reconoce un momento "en y fuera del tiempo" en el ritual que evidencia un tipo de vínculo fuera -y, a su juicio, en contraposición- del tejido social institucionalizado que da cuenta de la sociedad en cuanto comunidad "sin estructurar (...) y relativamente indiferenciada, de individuos iguales que se someten a la autoridad genérica de los ancianos que controlan el ritual" (1988, p. 103). La communitas que permite, paradójicamente, la coexistencia entre la indeterminación y la formación, tiene un aspecto existencial para el neófito, pues este, al no ser visto desde alguna particularidad, es concebido como una totalidad, lo cual sucede también con los otros iniciados. Si, por tanto, pensamos en que el principio de diferenciación del punto de vista humano, según el perspectivismo amerindio de Viveiros de Castro, se forma a partir del cuerpo, debemos centrarnos en la manera en que este transita por el rito de paso, con especial énfasis en la liminalidad y communitas, puesto que es a partir de allí que el cuerpo adquirirá su mayor grado de alteridad y diferenciación. En esa línea, creemos que un

Es importante resaltar que no se tiene pretensión alguna de abordar exhaustivamente el tema debido a su enorme complejidad, por lo que nos hemos centrado tan solo en algunos aspectos que consideramos que pueden ser de utilidad para nuestro análisis. 
punto importante de referencia y aquello que permitiría dar cuenta de esta transición son las danzas, dado que en ellas se puede observar la misma paradoja común a la communitas desde el mismo cuerpo - dicho sea, a pesar de ser una expresión de una totalidad indiferenciada son, al mismo tiempo, formativas de la diferencia-, por lo cual son capaces de marcar las tres fases de su transformación para constituir al neófito ontológicamente siempre en relación con otro.

Por otra parte, el material del análisis consta de cuatro danzas grabadas en los videos "Wapté Mnhõnõ" dirigido por Divino Tserewahú y "Xavante Hö" de la APSIRE (Associaçao de Proteçáo Social Indígena E Recuperaçao Ecológica). Estos videos están disponibles online en la plataforma Youtube y las referencias pertinentes se encuentran en la sección final de este trabajo. Dado el contexto actual de pandemia (o COVID-19) en el que nos encontramos, el acceso a fuentes ha sido limitado. Aparte de los documentos fílmicos mencionados, algunos estudios etnográficos disponibles al respecto sobre los Xavante u otros de los grupos Gê han sido de mucha ayuda. Aunque, ciertamente, la naturaleza de la aproximación puede también presentar ciertas limitaciones -frente a, por ejemplo, a un complejo y enriquecido acceso de trabajo de campo "directo"-, si quisiéramos resaltar que los documentales escogidos poseen puntos de vista interesantes: "Wapté Mnhõnõ" es dirigido y filmado desde la perspectiva de algunos Xavante, la voz en off en ambos vídeos consta de los mismos testimonios de los Xavante, estos testimonios provienen de Xavante de distintos grupos de edad, entre otras cosas, lo cual nos permite aproximarnos un poco más al discurso que se construye $-\mathrm{y}$ vive- en torno al rito de paso en cuestión.

En esa línea, el presente trabajo posee una parte descriptiva sobre lo que puede observarse en dichos videos, lo cual servirá para desarrollar el análisis según los conceptos del marco teórico. La metodología a utilizar para el análisis de las danzas enfoca la manera en que el cuerpo se sitúa en el espacio. Dada su importancia, la forma en que se mueva será crucial para el proceso gradual de diferenciación en la perspectiva. Según von Laban (1987), durante el movimiento hay dos actitudes corporales determinadas por dos formas de acción: ir del centro del cuerpo hacia la kinesfera y viceversa. Una forma de movimiento que conecta ambos aspectos y coincide con el uso ritual es, como mencionamos, la danza. Esta es la forma de poner el pensamiento en movimiento $\mathrm{y}$, a su vez, será fruto del esfuerzo (o impulso interior que origina el movimiento) del hombre por tomar consciencia de su vida interna (1987). Según el análisis de von Laban (1987, p. 142), estos son los elementos involucrados en la comprensión del "esfuerzo": el tiempo, espacio, flujo y peso. En este análisis solo haremos énfasis en el peso y la distribución del espacio. Debemos agregar, asimismo, que, en líneas generales, el esquema formal de análisis coreográfico que estamos utilizando es el de Kurath. Dicho en breve: (i) coreografía y estilo -con énfasis en la disposición geométrica y la estructura-, (ii) "interpretación" (que podríamos entender quizá como la dimensión 'social' de la danza) y (iii) "aspectos psicológicos" (en Citro, 2012, pp. 28-29). A partir de la crítica de Kaeppler y Citro (Citro, 2012) a este modelo, hemos intentado integrar el punto 
de vista interno sobre la danza -esto es, la perspectiva de quienes danzan a partir del testimonio- en este último punto del análisis. Asimismo, intentaremos incorporar algunas preguntas planteadas por Bardet (2012) y von Laban (1987): ¿Qué partes del cuerpo se usan? ¿En qué direcciones espaciales se mueven? ¿Qué grado de energía consumen? Y, al mismo tiempo, ¿quién hace la danza y quién decide?, ¿qué cuerpos son los que conforman la danza? Por otra parte, ya que el material a utilizar es sumamente extenso y complejo, hemos seleccionado cuatro danzas involucradas en el rito de paso: la danza del pop'wara, la danza de la guerra, la danza de los padrinos y la danza del sol, las cuales se corresponden con los estadíos preliminares, liminares y posliminares del rito de paso.

\section{Bailando lo sagrado}

La formación de los Xavante no es una cuestión trivial. Por el contrario, es aquello que permitirá que puedan adquirir la condición de "personas" plenas (Fernandes, 2010, p. 455). Un tipo importante de formación que seguirán los hombres Xavante se encuentra en los grados de edad del ciclo de vida masculino. Siguiendo a Graham (1995, p. 96), podemos dividir este ciclo en un periodo preiniciación, un periodo de iniciación y un periodo pos-iniciación, en el que, ocurrida la muerte, se hallan los "inmortales". En estos periodos, los hombres Xavante adquieren, a través de diversas ceremonias, entre cuatro a seis nombres: los no iniciados pueden ser, en líneas generales, aï'ute (bebé), waptebremi (pequeño niño), airepudu (chico) y wapté o hö'wa (residente de la casa Hö); los iniciados son 'ritai'wa; los hombres maduros ya iniciados son ïpredup-te (nuevo adulto, padrino de un wapté), ïpredu (completamente maduro) e ï-bi (anciano) -aunque, generalmente, no se tiene un nombre en esta etapa-; finalmente, los inmortales pueden ser wadzaparï'wa o abazschire, y höimana'u'ö (aquellos que, en su vida pasada, fueron personas excepcionales) (Lopes da Silva, 1989, pp. 334-335; Graham, 1995, pp. 96-101). Debemos resaltar que, por un lado, la adquisición de estos nombres es variable y puede prescindirse de algunos de los primeros, por ejemplo, cuando se considera que el niño es todavía muy vulnerable para cargar con el peso de tener un nombre; y, por otro lado, los nombres son expresión de principios ontológicos a través de los cuales se conciben a los seres humanos, o, dicho en otras palabras, "los Xavante abordan el concepto del sí mismo a través de diferentes prácticas de nomenclatura" (Lopes da Silva, 1989, p. 332). Esto último, especialmente, es de nuestro interés, puesto que nosotros buscamos aproximarnos a la concepción ontológica sobre el Xavante presente en el periodo de iniciación -después de algunos años en la estancia de solteros $H \ddot{o}-$ de los anteriormente waptes y, prontamente, 'ritai'wa. En ese sentido, volviendo a Van Gennep (2008) y Turner (1988), nos interesa, justamente, el paso de la liminalidad a la posliminalidad $y$, por consiguiente, las danzas que exploraremos serán parte de los ritos ejecutados en el margen y ritos de agregación.

Los jóvenes Xavante pasan aproximadamente cinco años en la casa de solteros (o $H o ̈)$, en la que -cual periodo de liminalidad-son aislados del resto de Xavantes, se 
le despoja de atributos de preiniciación y viven como un solo cuerpo. La estancia en la $H \ddot{o}$ es este momento "en y fuera del tiempo". Dentro del grupo de edad secular, el suceso más importante no es, con todo, el ingreso a la casa de los solteros, sino la misma iniciación que culmina con la ceremonia de agregación de perforación de las orejas del wapté y le permite ingresar a la sociedad adulta masculina (Graham, 1995). Visto desde una perspectiva ontológica, aquí toma lugar aquel momento paradójico que mencionábamos con antelación: el periodo de liminalidad en el que los wapté de una mitad se despojan de sus atributos y se hacen un cuerpo coincide con el proceso de maximización de la alteridad frente a la otra mitad. De esta manera, recuperando lo que vimos anteriormente sobre Viveiros de Castro, el proceso de diferenciación del Xavante durará toda su vida y deberá probarse constantemente. La generalidad de su cuerpo necesita hacerse mucho más propia, mucho más Xavante y, por lo menos en el caso del varón, ello se llevará a cabo de forma pública. En efecto, como señala Cristóvão Paridzané: "Ninguno se torna Wapté de manera oculta ni las madres hacen un trabajo escondido, sino presentándolo a toda la comunidad" (APSIRE, 2014, 16m38-16m56). Las danzas que analizaremos a continuación son una muestra de, por un lado, este proceso en el que se afianzan los lazos de parentesco con una de las mitades; y, por otro lado, crece la alteridad y oposición a los afines o miembros de la otra mitad. Una manera de ver esto es a través de los involucrados en la ceremonia de iniciación: los padrinos ${ }^{5}$, los rivales y fiscalizadores, y los iniciados. Los iniciados pueden ser parte de cualquiera de las dos mitades -en los casos que nos corresponde ver son los Etêpa y los Nodzö'u, ambos en distintos periodos de tiempo-, los rivales y fiscalizadores (así como también los afines) son parte de la mitad contraria a la de los iniciados, y los padrinos son aquellos que se iniciaron hace ya 14 años, también de la misma mitad que los iniciados. Como puede verse, por tanto, en una de las ceremonias más importantes dentro de la mitad que se ocupa de los grupos de edad confluyen la identidad y la alteridad, la semejanza y la diferencia, de manera tal que todo el proceso se tiñe de dinamicidad. Finalmente, remarcamos que no podemos profundizar en todo el ritual del paso por la Hö, sino que insistiremos en algunos aspectos de este en función a las danzas que hemos de estudiar.

\section{La danza y lo sagrado}

La primera danza que veremos será aquella que se performa en torno al pop'wara. Esta danza está registrada en el material filmico "Xavante Hö" de APSIRE (2014, $3 \mathrm{~m} 13 \mathrm{~s}-4 \mathrm{~m} 25 \mathrm{~s}$ ) y parece marcar el paso a la incorporación de los jóvenes Xavante a la casa de los adolescentes. El testimonio siguiente da cuenta de la conexión entre las dimensiones de cultura, naturaleza y supernaturaleza que no logramos expresar

\footnotetext{
4 Debemos precisar, con todo, que aquí parece cumplirse lo que señala Van Gennep (2008, pp. 100-103): estos ritos de iniciación no son ritos de pubertad física, sino de "pubertad social", dicho sea, los cambios fisiológicos que puedan tener lugar en el cuerpo de los jóvenes Xavante no marcan la pauta para estas ceremonias.

Debemos mencionar que también hay madrinas involucradas en la "danza de los padrinos", pero, lamentablemente, no hemos encontrado material disponible que nos ayude a profundizar en este punto. Su aparición en las grabaciones es también muy reducida.
} 
respecto a este proceso, pero que conforman el perspectivismo amerindio de Viveiros de Castro: "Jamás pueden jugar, como cosa sagrada solo puede servir para hacer la danza" (APSIRE, 2014, 3m44s-3m55s). El pop 'wara, un objeto sagrado, solo puede servir para danzar. En la escena puede observarse a un Xavante -posiblemente por el tamaño de báculo ("batoque" en portugués) que lleva en su oreja es un ïpredu, con parte del cabello pintado de rojo, así como el estómago y el resto del cuerpo de negro, junto a la característica corbata Xavante y las orejas perforadas- que funge de encargado del paso por la $H \ddot{o}$ de un grupo anterior a los Nodzõ'u-el grupo de edad que entrará a la Hö en esta filmación-y debe dejar el pop'wara en una de las malocas en las que todos están reunidos para que los nuevos jóvenes reconozcan su valor. El pop'wara es un objeto sagrado conformado por lo que parece ser un conjunto de plumas de diferentes animales atado por una cuerda de hilo vegetal. Lo que menciona, en realidad, es demasiado interesante: sobre las cosas sagradas solo puede danzarse. ¿Por qué, precisamente, la danza pone en contacto al Xavante con lo sagrado? Por el momento creemos que, en parte, podría deberse a que ejemplifica visual y auditivamente la necesidad de evocar en el movimiento y la repetición el mayor rango de alteridad -la sacralidad-para rememorar, repetir y enseñar no solo la conexión existente entre este y la identidad Xavante, sino también los lazos que ligan a los grupos de edad involucrados en el ritual. Esta respuesta no da cuenta de por qué, en todo caso, la danza tiene la capacidad de vincular lo secular con lo sagrado, por lo que volveremos al tema posteriormente. El pop'wara, con todo, aperturaría este momento porque, en palabras de Cristóvão Paridzané, sin él las danzas no tendrían vida y las canciones no tendrían un sentido (APSIRE, 2014, 4m20s-4m38s).

\section{Figura 1}

APSIRE, 2014, 4m40s.

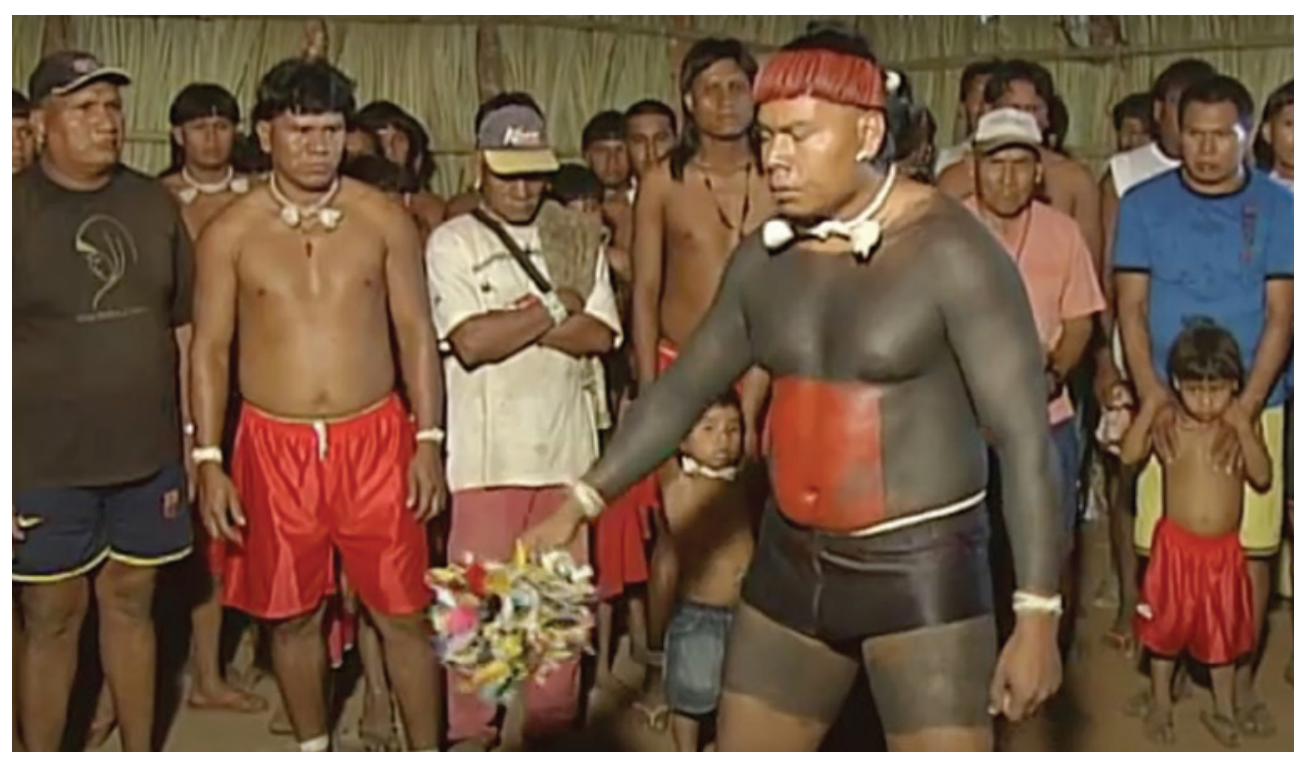


No es casual, entonces, que el pop'wara se deje en el centro de la maloca, como foco de la lucha que precederá al baile ceremonial. En esta breve lucha entre un Xavante mayor - un ïpredu- y un Xavante mucho más joven -en apariencia, un ïpredup-te-, sin duda, es el primero quien posee el derecho de tocar el pop'wara. Quien toca el objeto sagrado, sin embargo, pareciera no ser solamente él: sus movimientos nos indican una ferocidad animal que advierte al Xavante más joven sobre aquello que está en juego, la prueba de su coraje ante aquellos con los que, posiblemente, guarde mayor afinidad. De forma más descriptiva, vemos que el Xavante mayor empieza un movimiento que nos recuerda a la predación y al ataque. Tiene las dos manos como un puño y se mueve hacia el Xavante joven; después realiza un movimiento de lado, con un puño, su mirada y la mitad de su torso hacia aquel. La intensidad retenida a través de su respiración se manifiesta con fuertes pisadas que azotan el suelo. Solo después de dicha performance puede el Xavante mayor amarrar el pop'wara a una de las piernas del Xavante más joven, quien hasta el momento solo había permanecido mirando hacia el suelo, en silencio. Este silencio pareciera ser análogo al silencio selectivo del que habla Graham (1995) al dar cuenta de aquellos que pudo apreciar y estudiar entre los Xavante. Según la autora, el proceso de maduración social está marcado a través del sonido y el control de las formas de expresión (1995); es decir, a medida en que los jóvenes maduren irán progresivamente expresándose con mayor soltura ante los miembros de otros grupos de edad y ante los afines. El silencio del Xavante joven involucrado en la danza se expresa también en la manera en que maneja su cuerpo pues, como mencionamos, este está prácticamente inmóvil. Si pensamos esto en los términos del análisis de Von Laban (1987), el Xavante mayor ingresa desde la kinesfera del Xavante menor hasta el centro de su cuerpo sin que este oponga resistencia, posiblemente porque, siguiendo el análisis de Viveiros de Castro (2015), su identidad todavía está al inicio del proceso de diferenciación; su visibilización -y, en cierto sentido, el inicio de su movimiento- se relacionan con la concesión que el ïpredu le otorga al amarrar el pop'wara a su pierna derecha.

Esta danza apertura lo que, siguiendo el trabajo de Van Gennep (2008) y Turner (1988), llamamos estadío liminar para los adolescentes que han de ingresar a la $\mathrm{Hö.}$ Pese a la brevedad de esta danza, hay algunos puntos respecto a la conformación ontológica en este periodo que podrían sugerirse. Para empezar, si recordamos que el cuerpo permite la alteridad entre perspectivas y que, por ende, para afirmarse identitariamente uno tiene que diferenciarse corporalmente lo más que se pueda, en las formas de danzar pueden expresarse los grados de diferenciación por lo que pasa el cuerpo del Xavante: de ser un cuerpo en apariencia indistinto a ser un cuerpo particular, transformado a partir de las exigencias físicas del movimiento, la danza y el ritual. Por lo mismo, de la construcción de identidad no puede desligarse la alteridad en sus diversas formas (como predador, como otra mitad, como algo sagrado), incluso respecto a la sacralidad porque, como hemos visto a través del pop'wara, esto pareciera manifestarse mediante el cuerpo, justamente porque mediante el cuerpo aprehendemos dicha alteridad. Esto, como será visto más 
adelante, de alguna manera brinda una respuesta al por qué es que el proceso de formación ontológica en esta liminalidad pareciera caracterizarse por el desarrollo de los sentidos visuales y auditivos porque estos vinculan a la persona a algo otro: se ve y escucha a algo o a alguien. La presencia de la danza sugiere algo en esta misma línea, dicho sea, que un cuerpo danzante se conforma ontológicamente ligándose a otros cuerpos, otras sensibilidades - o a una posible communitas siguiendo el trabajo de Turner (1988)-, otras energías internas, ya sea por parentesco o por afinidad. El que el cuerpo se haga danzante y cantante con la misma maestría de aquellos grupos de edad mayores ya iniciados -lo cual, como será visto más adelante, puede verse en la capacidad de cada danzante de replicar los pasos o cantos del otro sin mayores alteraciones, con uniformidad- será una consecuencia de la efectividad con la que curse aquel proceso interno paradójico dado en la liminalidad al que nos hemos referido ya anteriormente: la coexistencia entre la indeterminación y la diferenciación del neófito. Anteriormente fue mencionado que, según el testimonio de Cristóvão Paridzané, sin el pop'wara las danzas no tendrían vida ni las canciones un sentido. Esto llama nuestra atención porque en esta danza, precisamente, puede verse que para el Xavante lo sagrado no es algo que se deje en el aparador y se venere. Por el contrario, pareciera que es algo con lo que se vive porque la danza, al llevar al límite al cuerpo humano, puede plasmar la energía de la vida. Esto nos lleva a la siguiente danza.

\section{La danza de lucha}

Ahora debemos centrarnos en una danza, precisamente, que lidia con los límites: una danza de lucha. Esta danza también está registrada en el material filmico "Xavante Hö" de APSIRE (2014, 9m34s-15m50s) y da cuenta de una competencia entre las mitades pö'redza 'ōnō y owawē en virtud de la descendencia patrilineal de los jóvenes. Notemos primero que esta danza es performada no solo por los waptés, sino también por waptebremi y airepudu. La diferencia, sin embargo, es que la manera en que se performa en estas dos últimas edades no pareciera exigir físicamente tanto como sí entre waptés, posiblemente por las fuerzas de aquellos muchachos pequeños aún en crecimiento. Estos, a diferencia de los waptés, son supervisados por sus padres, quienes, al ver que alguno de los chicos o niños ya no puede continuar luchando, le permite retirarse de la batalla a pesar de que eso signifique "perder", $y$, asimismo, al ver que el otro niño ya no puede seguir, el padre del "ganador" le impide a este seguir luchando $(2014,10 \mathrm{~m} 35 \mathrm{~s})$; los wapté, en cambio, son supervisados por ïpredup-tes, cuyo rol es ciertamente diferente.

Al narrar de qué trata esta danza, Daniel Tsi'õmowe menciona que a todos les gusta mucho el evento y sonríen al ganador, pero esta pelea es por quién es un hombre: en esta danza se prueba que el valiente es considerado un hombre (APSIRE, 2014, $10 \mathrm{~m} 50 \mathrm{~s}-11 \mathrm{~m} 20 \mathrm{~s}$ ). Se performa a la intemperie, fuera de la maloca. El sujeto, el cuerpo, atravesará por este proceso a través de la lucha con un otro, con alguien 
que, al tener un cuerpo similar, es potencialmente otro sujeto. De esta manera, el acontecimiento se enmarca en un ecosistema de relaciones cruzadas entre seres: cuando un Xavante, pareciera, se presenta como ganador, se presenta ante cualquier espectador. Se hace valiente porque ha demostrado que aprendió a luchar; dicho antagonismo nos sugiere, pues, que tanto la persona como la realidad no subsisten ni aisladas ni en completa afinidad. El dinamismo de la persona que repite el orden cósmico reside en un juego de oposiciones encarnadas que llevan al sujeto al límite. El joven Xavante, como veremos en las otras danzas, siempre estará enfrentado a sus propios límites establecidos por su cuerpo, pero también por la presencia de otros afines; de forma inversa, por ende, podríamos decir que hay una consciencia clara de la vulnerabilidad humana en la manera en que se concibe su ser. En un entorno en que cada perspectiva vive legítimamente en su propia realidad, la existencia puede perderse en cualquier momento, por ende, se debe demostrar que uno es capaz de cargar con el peso de la perspectiva humana que se representa a través de nombres. En efecto, el testimonio de Daniel Tsi'õmowe pareciera confirmar esto, puesto que, como menciona, es válido que a un Xavante no le guste luchar; es más, "puede estar tranquilo" si es así, pues ya ha aprendido a ser un hombre en la pelea (APSIRE, 2014, 11m20s-11m36s). Esta idea será clave para la concepción ontológica de la persona que se esboza en la danza porque pareciera que el cuerpo que danza es un cuerpo que está en una constante lucha por su identidad, sobre todo en el periodo preliminar y liminal.

Ahora bien, iniciemos nuestro análisis describiendo la estructura general de esta danza. Cuando los Xavante jóvenes y niños bailan lo hacen a través de diversos círculos concéntricos en el espacio que se halla entre las malocas. Se mueven tan solo en las líneas imaginarias que delinean el contorno de ese círculo; en el círculo siguiente que contiene a este se hallan ïpredup-tes, quienes, a diferencia de los padres de los waptebremi y airepudu, alcanzan las armas de lucha, esto es, los huesos de animal. Tal como puede verse en el análisis de Graham (1995) sobre la primera aparición pública de los wapté en su investigación, los danzantes en este caso, quienes pertenecen a una de las mitades, en este material fílmico se mueven en sentido contrahorario. El movimiento de los pies balancea el peso del cuerpo, no se queda todo en un solo lado, o en una sola de las piernas, por lo que pareciera una danza en la que se intenta preservar el balance del peso aun en el ataque. Aquí puede notarse claramente la diferencia entre la manera en que luchan los waptebremi y airepudu frente a los wapté: a los primeros se les dificulta en demasía danzar mientras luchan, en apariencia, debido a la manera en que soportan el dolor de los golpes; por consiguiente, en algunos casos, los niños no terminan el círculo, sino que luchan en el mismo lugar, mientras que los airepudu, aunque sí pueden danzar en círculo, no resisten mucho tiempo antes de que uno de los participantes se rinda. Esto es interesante porque, a diferencia de estos, los wapté atraviesan el dolor para continuar danzando en círculo durante más tiempo; y, al observar sus movimientos, su sincronía pareciera dar la ilusión de que el peso propio del danzante no se ve impedido por el dolor para expresarse o diferenciarse, tal como si fuera ligero. 
Figura 2

APSIRE, 2014, 12m04s.

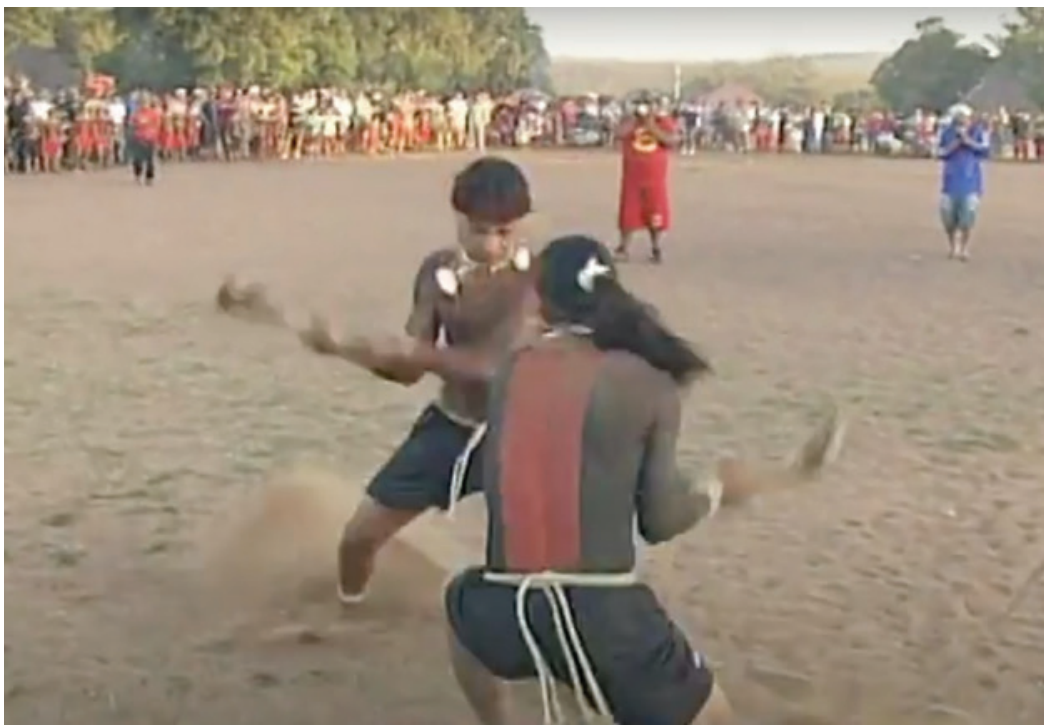

En la misma danza, los golpes son laterales y muy fuertes -este último calificativo se juzga en función de las expresiones de dolor de los involucrados-. Como vimos en el caso del pop'wara, el centro representa la vigencia de la alteridad. Siguiendo el análisis de Eliade (2000), podríamos pensar que dicho enfrentamiento, en un primer nivel, podría representar la actualización de un drama cósmico expresado en mitos. A esto quisiéramos agregar que, asimismo, si integramos la posición de Viveiros de Castro (2015) expresada en el marco teórico, en juego puede estar también el modelo de predación como forma de relación entre las distintas perspectivas. Mientras tanto, nótese que el cuerpo que danza y lucha ya se ha transformado: primeramente, a través del color rojo que tiñe el pelo, la indumentaria propia del ritual y, sobre todo, a través de las emociones y el dolor que experimentan ambos luchadores. Es interesante que los golpes estén dirigidos hacia los brazos. Los brazos y las piernas permiten un mayor uso del campo de movimiento propio de cada cuerpo, pero, a través del golpe, los brazos permiten que el Xavante experimente de forma más dramática el peso y la gravedad ${ }^{6}$. El peso no es, por tanto, algo que

\footnotetext{
6 Respecto a la pertinencia del peso como una categoría de análisis en el caso de las danzas Xavante analizadas, agradecemos en demasía uno de los comentarios realizados por un revisor anónimo de este texto. ¿Es relevante la categoría de "peso" en un análisis como este? ¿No estamos desviando la mirada de las categorías de los Xavante para referirse a las danzas? Nuestro revisor sugirió, en esa línea, introducir testimonios Xavante que sustenten explícitamente la presencia de las categorías de peso/ligereza, ya sea mediante los videos utilizados como el trabajo de campo. Al respecto, queremos comentar lo siguiente: aunque en el material filmográfico revisado (tres videos de distinta duración) no se han encontrado testimonios verbales sobre la presencia del peso/ligereza, esto no anula necesariamente la pertinencia de la aplicación de estas categorías, por lo que en realidad sería necesario realizar un trabajo de campo. Ciertamente, las condiciones actuales no son propicias para realizar un trabajo de campo; sin embargo, debemos precisar algunos posibles alcances sobre el particular. Para empezar, nos parece que la presencia de la categoría de peso puede (i) pensarse a partir de un paralelo con la presencia del peso en el nombre testificado en otros estudios, (ii) verse a nivel de prácticas en la forma de actuar Xavante involucradas en el ritual. El primero de los puntos es tratado en el cuerpo del texto directamente, por lo que debemos centrarnos ahora brevemente en este segundo punto. A nuestro juicio, la relevancia del peso pareciera estar presente en el ritual de
} 
se quiera evitar o abstraer -como, según Bardet (2012), es característico de algunas ontologías occidentales-; por el contrario, es a través del peso que se realiza la construcción de la persona Xavante. A medida en que más puede soportarse el propio peso es que el individuo se hace ser humano, o, en otras palabras, se está en camino de convertirse en una persona plena. Frente a este panorama, es importante volver sobre un tema que se ha tocado muy ligeramente algunos párrafos atrás: el peso del nombre. Fernandes (2010, pp. 461-462) señala que, al inicio del ciclo de vida masculino, esto es, en el paso del aï’ute (bebé) hasta el waptebremi (pequeño niño) aproximadamente, el cuerpo de los pequeños Xavante se considera como "blando" (en portugués, mole). Al ser "blandos", sus cuerpos son muy vulnerables y frágiles, están abiertos a influencias externas -probablemente porque todavía no se ha diferenciado el punto de vista humano lo suficiente como para ser propio- y no tienen un nombre, esto es, todavía no son considerados como personas plenas. Ya que tener cargar con el peso de un nombre es una expresión de la conquista o del aumento de la fuerza vital (Lopes da Silva en Fernandes, 2010), lo cual no es posible en esta etapa, se utiliza como medio mágico para salvaguardar la salud de los pequeños, unos dañipsi, esto es, unos hilos de fibra vegetal pequeños con propiedades mágicas que se colocan en el cuello y en las muñecas para poder, a juicio del autor, demarcar los límites de lo humano (Fernandes, 2010).

$\mathrm{Si}$, entonces, al iniciar este proceso de formación el cuerpo es blando y sumamente frágil, dicho proceso culminaría con un endurecimiento del cuerpo Xavante. Con todo, uno podría cuestionarse por qué, si el peso no se abstrae, el cuerpo Xavante puede moverse con tanta naturalidad al bailar, a pesar de ser cada vez más duro, tal como puede apreciarse en el material fílmico en el que nos basamos (APSIRE, 2014). Una respuesta podría hallarse en aquello que menciona Lopes da Silva, esto es, en este proceso el Xavante adquiere simultáneamente una mayor fuerza vital. Ahora bien, quisiéramos volver brevemente al análisis de Bardet, pues nos permitirá pensar en otra posibilidad al respecto. En la primera parte de su estudio sobre la relación entre la filosofía y la danza, Bardet (2012) 7 identifica una tendencia a concebir a la danza como una metáfora del pensamiento en la que la pesadez y la ligereza se oponen y, en la medida de lo posible, se excluyen. Así, la bailarina de ballet ha servido a la reflexión del filósofo -según la autora- como aquel cuerpo que es liberado de sí mismo, de su peso y género a favor de ligereza, frente al cuerpo que experimenta el peso de manera pesada y violenta, propia del cuerpo

iniciación, por ejemplo, a partir de la manera en que se puede observar el uso del peso al momento de pisar marcando la tierra en la danza de los padrinos, en el balance del peso utilizado para luchar bailando, en el hecho de que en una de las carreras realizadas por los padrinos estos cargan un tronco de más o menos 80 kilos entre varios miembros durante 6km, que es, de hecho, para los Xavante, "una de las formas divertidas de hacer el ritual" (Costa, 2016, 9m38s; 10m08s). Asimismo, en el resto de este texto hacemos referencia a aspectos como estos que, aunque no sean mencionados verbalmente, sí están presentes efectivamente en el material filmográfico observado. Es en ese sentido que nos parece que puede pensarse una correspondencia entre la manera en que los Xavante conciben el ritual y la presencia de las categorías de peso/ligereza en este, pero, con todo, sí consideramos que en un trabajo posterior y sobre la base, desde luego, de un trabajo de campo, podría profundizarse mucho más al respecto.

7 Aquí solo nos referiremos al análisis que hace la autora de los planteamientos de Badiou y Válery en función a lo que nos puede servir para nuestro análisis. En esa línea, no nos es posible ahondar más en el tema ni tampoco en los otros autores que son estudiados en su obra. 
"militar" en el análisis de Badiou (Bardet, 2012, pp. 36-38). De esta manera, solo la primera experiencia del cuerpo que procure abstraerse de sí mismo permitiría la realización de la supuesta ligereza y rapidez del pensamiento. Otra tendencia puede verse representada en dos momentos del planteamiento de Válery. En un primer momento introductorio, este posiciona a la bailarina como una medusa, dicho sea, como símbolo de la ligereza absoluta y de la movilidad en todos los sentidos, lo cual implica "la ausencia de todo suelo, de toda solidez exterior, como de toda solidez interior: cuerpo sin huesos, sin articulaciones" (Bardet, 2012, p. 44). En un segundo momento, en cambio, al reflexionar a partir del enfoque del suelo en la obra Danseuse sur la scène (1876) de Edgar Degas, Válery postula que el suelo es un plano que nos permite visualizar distintos aspectos del movimiento, la duración y peso de la bailarina a través de la luz. El suelo nos permite ver la manera en que se desplaza y transforma el esfuerzo interno de la bailarina (Bardet, 2012), así como su relación concreta con otros danzantes. Esto es, el suelo nos permite presenciar los distintos movimientos e intensificaciones de los cuerpos. En suma, entonces, en el planteamiento de Badiou y la postura introductoria de Válery -que nos recuerda mucho al primero- podemos observar un intento de abstraer el tiempo y el suelo, pero, concretamente, sin suelo ni tiempo no hay danza. El segundo momento en la reflexión de Válery nos permite pensar las cosas de manera diferente porque no se insiste en una contraposición excluyente entre peso y ligereza, sino en el vínculo inevitable que surge entre ambos al momento de danzar. Asimismo, un enfoque que no prescinda ni del tiempo ni del peso permite incluir en el análisis también lo que significa, para el individuo danzante, la experiencia misma de estos elementos -no necesariamente de forma aislada, sino contando con las otras corporalidades con las que la danza nos une y diferencia.

Con esto en consideración podemos volver a la interrogante que planteamos anteriormente, dicho sea, por qué, si el peso no se abstrae, el cuerpo Xavante puede moverse con tanta naturalidad al bailar, a pesar de ser cada vez más duro. La respuesta que sugerimos es que, frente a la abstracción del peso, aquí nos encontramos con una integración progresiva del significado del peso para el danzante. Esto es, corrigiendo una expresión anterior, en las etapas superiores de la formación que viviría el Xavante el peso se integraría de tal forma a la experiencia que ya no se "soportaría", sino que se viviría. Abstraer el peso significaría prescindir de la experiencia de valor y coraje necesarios para ser una persona plena; y, asimismo, podría significar también romper con un elemento fundamental en la concepción ontológica del Xavante, dicho sea, su vínculo con la tradición. Esto puede verse en el testimonio de Raimundo Urebeté (APSIRE, 2014, 6m00s-6m39s): "En nuestra convivencia hoy, no se practica por completo nuestra conducta de comportamiento, de educación, de respeto. Pero nos aseguramos de que los más jóvenes digan cómo lo hicieron los antiguos nuestros antepasados. Antes, las personas mayores eran más robustas y fuertes, a pesar de ser personas mayores, mantenían su fuerza, su energía para vivir y comportarse para dar ejemplo a los jóvenes", así como podemos inferir de los estudios de Lopes da Silva (1989), Graham (1995) y Fernandes (2010): ser 
capaz de cargar con el peso de un nombre significa ser capaz, al mismo tiempo, de acceder a la continuidad y regeneración cíclica que esta sociedad plantea a partir del uso de los nombres de los grupos de edad ${ }^{8}$.

Así que es factible que la tesis de Lopes da Silva (1989, p. 337), esto es, "los cambios de nombres a lo largo del tiempo indican el proceso de vivir las experiencias y transformaciones sociales que debe atravesar un individuo para lograr los atributos necesarios de un ser humano", pueda pensarse también en términos del peso, dicho sea, que el cambio de la experiencia del peso también es un indicador de la efectividad con la que se pasan las experiencias formativas que vive la persona que ha de transformarse constantemente hasta que alcance no solo los atributos necesarios para ser llamado un ser humano, sino también la condición de persona plena a la que nos referimos anteriormente. Es factible también que, siguiendo esta línea, el manejo del wapté de su propio peso con relación al suelo llega a un balance interno tal que le permite no solo sostenerse en pie de lucha, sino también -frente al waptebremi y al airepudu - tener la capacidad misma de relacionarse a través de la lucha con los afines (o la alteridad) y con quienes guarda lazos de parentesco, como puede verse en el caso de los ïpredup-tes. Pero esto sucede también porque el muchacho ha integrado progresivamente la presencia de un otro frente al cual contruye su identidad. La danza, entonces, pareciera tomar un lugar interesante en la preparación para la iniciación porque nos muestra que el manejo del peso corporal es parte del proceso de diferenciación de la perspectiva humana; asimismo, si seguimos la relación entre el peso del nombre y el vínculo que guarda con la tradición, la experiencia del peso a través de la danza permite que confluyan historia, política y ontología. Mediante los pies enterrados en el suelo de aquel muchacho que lleva consigo no solo su propio peso, sino también el peso de la marca corporal ejercida por el otro, se experimentan distintos tiempos en uno, en el propio tiempo que crea la danza. Están los ancestros, el otro Xavante, los espectadores y no-humanos ante los que el joven Xavante afirmará - a partir de su movimiento y, de manera más precisa, a través de actividades que lo lleven al límite como, en este caso, la luchaque él también es una persona y, sobre todo, que, en tanto portador del ser-persona, es valiente, tiene coraje, esto es, es Xavante. La presencia de este suelo simbólico y físico, podríamos decir con Valéry (1965), permite el movimiento y las infinitas posibilidades en las que puede expresarse el cuerpo.

\section{La danza de los padrinos}

La tercera danza que vamos a estudiar está registrada en el material filmico "Wapté Mnhõnõ" de Tserewahú (1999, 9m30s-9m50s, 23m25s-24m29s, 38m40s) y se denomina "La danza de los padrinos". Recordemos que los padrinos son aquellos

\footnotetext{
Es interesante notar que, según Maybury-Lewis (1967, en Da Silva, 1989, p. 335), los Xavante "conciben su sociedad a través de una ideología masculina. En la sociedad Xavante, los hombres son vistos como los guardianes de la cultura y la tradición, y son responsables de la continuidad de la sociedad", puesto que la experiencia del peso físico en la danza podría ser también una razón que sostenga este rol de los hombres Xavante.
} 
Xavante iniciados hace ya 14 años y pertenecientes a la misma mitad de edad que los ahijados. En los fragmentos que hemos de estudiar, los ahijados son los Etêpa, mientras que los Hotorā cumplirán el papel de los padrinos. La danza de los padrinos parece ser ejecutada en la misma semana en que se perforan las orejas de los muchachos Etêpa, por lo que concluimos que es una danza de agregación. Antes de pasar al análisis de esta danza, quisiéramos volver a una pregunta que planteamos anteriormente: ¿Por qué, precisamente, la danza tiene la capacidad de poner en contacto al Xavante con lo sagrado? Consideramos que lo que veremos a continuación nos permitirá dar un soporte a la respuesta que planteamos antes, esto es, al que la danza "corporaliza" visual y auditivamente la necesidad de evocar en el movimiento y la repetición el mayor rango de alteridad -la sacralidad- para rememorar, repetir y enseñar la conexión existente entre este y la identidad Xavante. En su estudio sobre la sociedad Xavante, Graham (1995, p. 114) señala que los Xavante adultos iniciados manifiestan haber "recibido" las canciones que han de cantar o bailar en sueños: "Según la mayoría de los adultos Xavante, tanto hombres como mujeres, los da-ño're individuales se originan con los inmortales y los creadores höimana 'u'ö, a quienes la gente ve y escucha en sus sueños". Aunque los adultos jóvenes no suelen reconocer a los hombres cantantes y danzantes que ven y escuchan en sus sueños, los adultos mayores sí los reconocen como los inmortales, como personificaciones de sus ancestros. Por otro lado, como señala Graham (1995), si bien es cierto que los sueños se presentan como experiencias individuales para cada uno de nosotros, podemos escoger el medio por el cual compartimos esta experiencia: hablando, escribiendo e, inclusive, cantando y danzando nuestros sueños. En ese sentido, hay un trabajo dialógico entre nuestra experiencia y elaboración estando despiertos (o "conscientes") y nuestra experiencia en los sueños. Esta dialéctica está presente también en el caso de los Xavante, quienes escogen representar públicamente sus sueños. La danza que los padrinos escojan bailar, por tanto, será fruto de la elaboración de un soñador que recibe la canción de sus ancestros. Es importante que notemos, con todo, que para los Xavante no cualquiera puede expresar su sueño a través de la danza: solo los adultos y los adultos jóvenes iniciados son capaces de presentar da-wawa (lamentos cantados) y da-ño're respectivamente. Los chicos y niños también suelen decir, según Graham, que escuchan canciones en sus sueños, aunque no las recuerdan del todo. Su capacidad de recordar se ve ligada a la culminación de su iniciación. Solo cuando el neófito ha pasado la fase liminar exitosamente y sea un 'ritaï'wa recordará lo que sueñe y, por ende, podrá expresarlo mediante el canto o la danza. Volveremos en un momento a este punto.

Ahora debemos aproximarnos a la ejecución de la danza. La danza de los padrinos que tendrá lugar cuando el joven Xavante, tras la prueba de chapotear en el agua que suele durar, aproximadamente, un mes y la perforación de orejas, haya salido victorioso, debe ser ensayada en repetidas ocasiones porque en el debut debe ser performada de forma perfecta. Como en el caso de la danza de lucha, esta también se realiza a modo de un círculo que gira alrededor de su centro. La actitud dancística de los padrinos es muy interesante: su postura no es erguida, sino que está regida 
por la dirección de su mirada hacia el suelo. Las piernas están flexionadas, como si estuviesen preparados para hacer un movimiento rápido en conjunto y como si, a su vez, formaran todo un cuerpo. Pero la presencia del aparente "vacío" en el centro nos advierte, de antemano, que probablemente sería un equívoco considerar esto una expresión de identidad pura. En realidad, incluso allí, el suelo es el primer otro con el que se baila y sobre el que el movimiento reflexiona. Los ensayos duran horas y se repiten, entre cantos, los mismos movimientos; se puede apreciar que los padrinos se quedan ensayando toda la noche hasta que sus cuerpos no resisten más y se desmayan (Tserewahú, 1999, 38m40s). La danza de quienes han de servir de modelos y apadrinar a los Etêpa muestra que estos, para llevar a cabo la danza de la manera más coordinada, llevan sus propios cuerpos hasta su límite. La cohesión se conseguiría, entonces, sobre la base del entrenamiento interno de cada Xavante. Por otra parte, para la presentación de dicho baile el cuerpo necesita ser primero transformado visualmente: a través de la pintura e indumentarias rojas, las soguillas y corbatas Xavante, los padrinos pueden finalmente ejecutar la danza. Si bien los pies no se entierran en el suelo como en la danza de guerra, sí son presionados fuertemente en la misma dirección. Según Lopes da Silva, "En relación con este "soñar", otro dato que pude recoger es que se trata de una actividad esencialmente masculina: las mujeres "no saben pensar", tienen "la cabeza rígida", dicen los hombres de Xavante" (1980 en Fernandes, 2010, p. 465) $)^{9}$. Aunque no podemos detenernos en el complejo contenido de esta cita, sí quisiéramos resaltar que, si la capacidad de expresar este soñar se consigue gracias a la formación interna y corporal que ha de llevar a cabo el Xavante durante años, entonces, la capacidad de pensar también se ha de desarrollar. Pero, si las danzas se escuchan y observan en los sueños, entonces las capacidades de visión y oído se desarrollan posiblemente de manera paralela. Así, el canto integrado en la danza, en específico, es importante si recordamos con Bardet (2012) que los pies escuchan el suelo a través de la danza y, de esa manera, trazan una relación con lo que ha sucedido en este: la vida de sus ancestros y de otros Xavante. A medida en que el Xavante se afirma en su punto de vista humano aumenta su capacidad de escuchar y, por tanto, de desempeñar con mayor eficacia y fuerza la danza. Esto puede observarse en una de las funciones simbólicas que poseen los batoques de los padrinos que danzan: sus perforaciones en los oídos, a diferencia de la de los jóvenes Xavante a quienes llevan catorce años de edad, son mucho más grandes. De manera análoga, su movimiento dancístico es mucho más libre y, por ende, pueden movilizarse de manera más flexible en el espacio. Como señala Fernandes (2010, p. 456), el cambio del tamaño de los aretes en los Xavante "significa... un aumento en la capacidad de aprender-oír-conocer" y, en esa línea, la capacidad de performar los sueños es un producto de dicho aumento en la capacidad de aprender y conocer, o de escuchar y observar.

\footnotetext{
9 Debido al tema del trabajo, no es posible que nos aproximemos a la concepción de la mujer Xavante, aunque sí se han encontrado referencias breves en los trabajos de Lopes da Silva (1989), Graham (1995) y Fernandes (2010).
} 


\section{Figura 3}

Tserewahú, 1999, 38m40s.

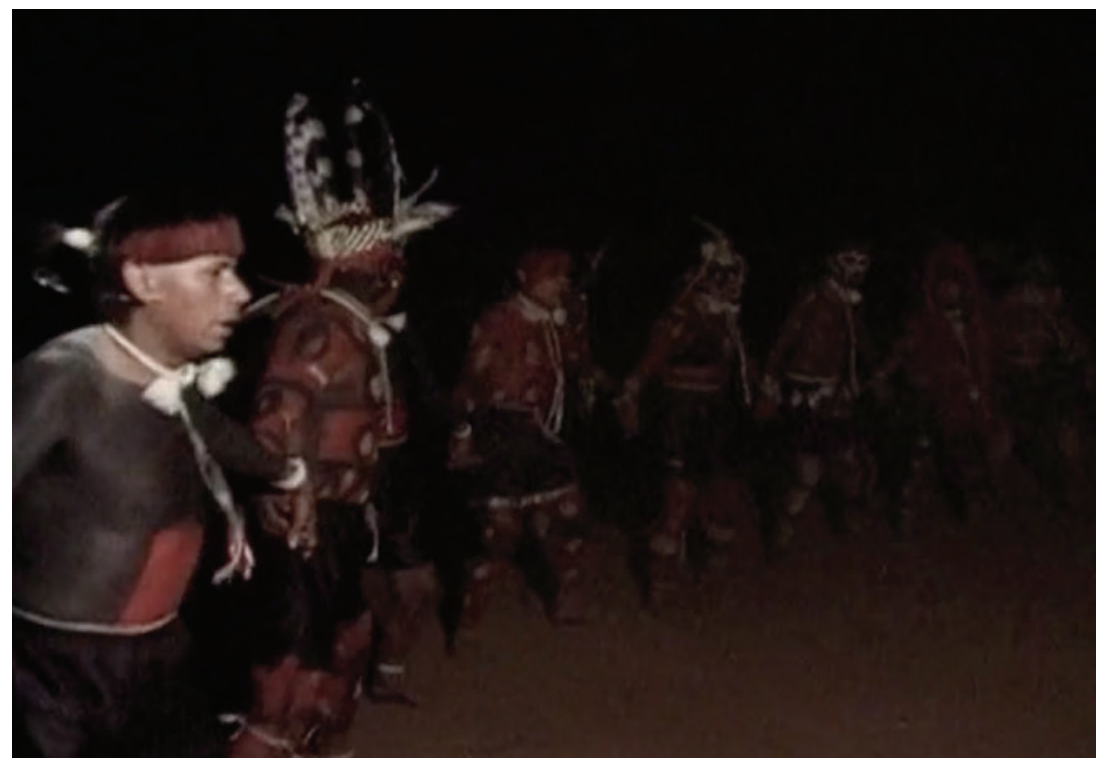

En la opinión de Graham (1995), las performances da-ño're-como la danza de los padrinos-son instrumentales para la creación y el mantenimiento de lazos afectivos entre hombres porque cantar y danzar enfatizan la cohesión del grupo y la identidad colectiva. De los puntos que podrían resaltarse al respecto, quisiéramos insistir en uno. En primer lugar, en el trabajo etnográfico de Graham (1995) y en el material filmográfico "Xavante Hö" de APSIRE (2014, 5m35s-5m51s) puede verse que los grupos de edad del ciclo masculino anteriores a la iniciación (esto es, waptebremi, airepudu y wapté) imitan las danzas de los mayores, entre las que se incluye la danza de los padrinos, con una importante diferencia: en su imitación se puede percibir las diferencias entre quienes son danzantes y cantantes. Así como cuando hablábamos de la danza de lucha mencionábamos que los waptebremi y airepudu no solían poder mantener el balance del peso de su cuerpo y luchar al mismo tiempo en que se mueven circularmente sobre un mismo eje, en este caso, sus pasos tampoco son uniformes, sino que varían según el danzante. Entre ellos, la diferencia individual es notable: vemos a seres individuales performando un mismo acto. Algo similar sucede con sus voces, pues algunas se escuchan más agudas que otras, con un tono más alto, entre otras cosas. En contraste con esta perspectiva, en el caso de los padrinos no se percibe con facilidad diferencia alguna entre sus voces y movimientos: la experiencia de cohesión es notable. Esta es, quizá, una de las instancias en las que se puede ver la communitas que plantea Turner (1988): en las performances da-ño're, como la danza de los padrinos, pareciera experimentarse un momento fuera del tejido social institucionalizado, una experiencia de totalidad que vincula a los danzantes y se somete solo a la autoridad de los ancianos. Esto nos lleva a lo siguiente. En "Wapté Mnhõnõ" se puede observar que los padrinos ensayan por meses la danza escogida y 
la presentan ante los ancianos para pedir su aprobación (Tserewahú, 1999, 32m28s). Al decidirse afirmativamente por esta, los ancianos también la performan entre ellos. Esto es interesante porque podría pensarse que la danza, a partir del proceso que se lleva a cabo para su performance en público, está atravesada profundamente por el ciclo de vida masculino. En otras palabras, la danza pareciera ser expresión del proceso externo a través del cual el individuo se sume en una misma experiencia de comunidad o totalidad con sus congéneres. Pero, si tomamos aquello que hemos visto anteriormente respecto a las características ontológicas que el Xavante va adquiriendo progresivamente, notamos que el pensamiento, la escucha, la comprensión y la visión que desarrolla están impregnadas de un matiz afectivo hacia la comunidad a la que pertenecen. A diferencia de lo que puede verse usualmente en ontologías occidentales, como, por ejemplo, en el estudio de Aristóteles sobre el ser en tanto ser, aquí lidiamos con capacidades (o dynamis) que no se construyen para un fin individual, aunque, paradójicamente, partan de la formación de distintos individuos. Los padrinos llevan a cabo su danza tomándose de las manos y girando sobre un mismo eje en sentido horario; este acto se ejecuta repetidas veces durante horas. La repetición permite que se absorba efectivamente al individuo en el grupo (Graham, 1995), por lo que el desenvolvimiento de los padrinos es una muestra del nivel de desarrollo de sus capacidades, especialmente, del oído, pues este está lo suficientemente formado como para poder recibir el mensaje de los inmortales a través de sus sueños y recordarlo. La performance de los padrinos, por tanto, es una muestra de aquello a lo que los jóvenes Xavante han de llegar si se convierten en personas plenas y, en ese sentido, son un modelo dialógico del encuentro entre identidad y alteridad.

\section{La danza del sol}

La última danza a la que nos referiremos sugiere también la presencia de este último punto. La danza del sol está registrada en el material filmico "Wapté Mnhõnõ" de Tserewahú (1999, 36m26s-9m50s) ${ }^{10}$. Quienes danzan son ïpredup-tes, por tanto, al ser ya adultos jóvenes iniciados han de tener ya desarrollados el oído, la capacidad de escucha, pensamiento y vista. El grado de diferenciación ontológica que posee el danzante, debido a su plenitud como persona, parece ir de la mano con los artilugios e indumentaria que lleva. Aparte de los pantalones cortos característicos, la corbata y las pulseras de fibra, llevan en sus piernas dos cascabeles situados en los objetos sagrados que cargan, esto es, los pop'wara. Esta danza se realiza dando zancadas con intención de aproximarse al astro solar mediante una coreografía en la que se traza el movimiento en un círculo. El análisis de nuestra primera danza nos mostró que la aprehensión de la alteridad -incluso la que vincula al Xavante al ámbito

\footnotetext{
10 Debemos mencionar que no nos es posible ahondar más en esta práctica debido a que, hasta el momento, no hemos encontrado información bibliográfica disponible al respecto. A pesar de que la dirección de los danzantes es siempre hacia el astro solar, no hemos podido profundizar en este punto por el mismo motivo. Sin embargo, hemos incluido esta danza por su importancia; ella da cuenta del proceso ontológico de desarrollo dinámico del Xavante al que nos hemos referido a lo largo de este trabajo.
} 


\section{Figura 4}

Tserewahú, 1999, 36m26s.

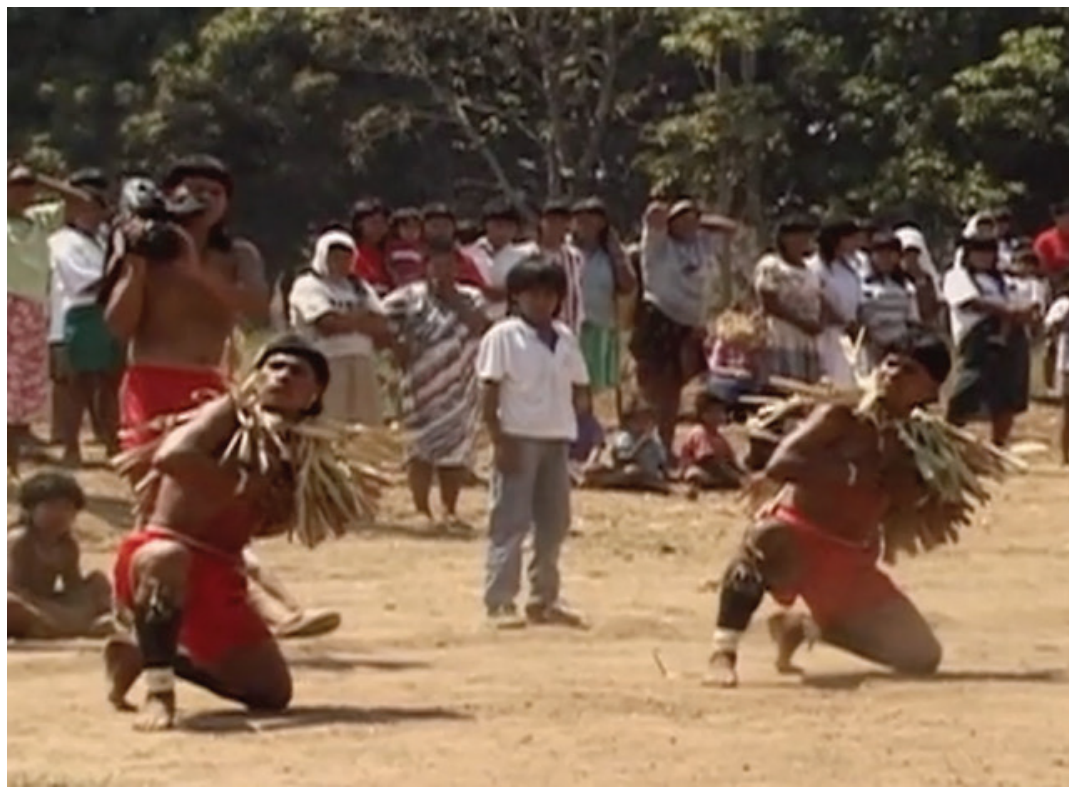

sagrado, propio de los inmortales- se da mediante el cuerpo: el pop'wara, como aquello que otorga sentido a las danzas y cantos, apertura esta instancia. Pero esto lleva a la construcción misma de la identidad en la diferenciación. Al momento de danzar, la pierna derecha del danzante golpea ansiosamente el suelo repetidas veces mientras él mira hacia el sol y se tapa el pecho con sus dos brazos. Si los danzantes se mueven en su kinésfera es para dirigirse hacia el sol. Con todo, hay una diferencia fundamental más que puede verse en el siguiente testimonio: "No es cualquier persona que puede ser Pahoriwa, el escogido para la danza debe tener el cuerpo perfecto, para que combine con los adornos" (Tserewahú, 1999, 37m). Para que uno pueda danzar con el pop'wara y, en esa línea, evocar la conexión con aquello que brinda sentido no solo al movimiento dancístico, sino también a aquello que lo sostiene desde la comunidad, uno debe tener el cuerpo "perfecto". Para que uno pueda danzar con el pop'wara y, en esa línea, evocar la conexión con aquello que brinda sentido no solo al movimiento dancístico, sino también a aquello que lo sostiene desde la comunidad, uno debe tener el cuerpo "perfecto". Aunque no nos es posible profundizar en este calificativo, podemos reflexionar brevemente al respecto sobre la base de lo que hemos visto hasta el momento. Si, siguiendo el trabajo de Viveiros de Castro (2015), el cuerpo, como sede de capacidades y afectos, es el principio de diferenciación del punto de vista humano, esto sugiere que un cuerpo perfecto podría ser aquel cuya corporalidad lo muestre especialmente como humano, esto es, que exprese plenamente su identidad Xavante. Si insistimos, además, en que aunque, a diferencia de las otras danzas estudiadas, en esta ninguno de los danzantes tiene contacto físico entre sí, ni hablan o cantan ni se dirigen la mirada, sus pasos 
son tan idénticos entre sí que parecieran reflejados ambos en un espejo, podríamos pensar en que el punto de vista humano Xavante que ha alcanzado su plenitud tiene como característica justamente esto: puede mimetizar al otro que no es él, tal como un espejo, sin perder su identidad. Por lo mismo, la construcción ontológica de la persona Xavante pareciera realizarse progresivamente sobre la base de la reflexión sobre la alteridad que, a medida en que se avanza en la formación, se hace más "consciente" y propia a través del cuerpo.

\section{Conclusiones}

Este trabajo representa una primera aproximación a la manera en que puede esbozarse una ontología Xavante. Con esta finalidad, como ha sido remarcado anteriormente, solo nos hemos centrado en algunos aspectos en torno a la manera en que se lleva a cabo el ritual de iniciación de los waptés, especialmente, a través de la danza. Sin pretensión alguna de exhaustividad, podemos concluir sobre la base del análisis y reflexiones realizadas que en la etapa en que nos hemos centrado del proceso por el cual el Xavante se hace "hombre verdadero" trabaja con los límites. A través de la experiencia del límite, sea en la danza de la lucha o en el mes que se entrena en el río antes de perforarse las orejas, es que uno se hace merecedor del adjetivo de persona plena. Este "adjetivo" es producto de una transformación ontológica, pues en el proceso el wapté ha desarrollado capacidades (o dynamis) como la capacidad de pensar, escuchar, luchar y observar, las cuales se mostrarán en su cuerpo danzante que ha tenido acceso a la capacidad de negociar la expresión de sus sueños a un primer nivel, que es "consciente" o autorreflexionado, y a un segundo nivel, frente a los adultos mayores de la comunidad. Este cuerpo danzante liga ontológicamente al Xavante a otras corporalidades, y con ello permite ver que el ser-Xavante implica también una experiencia afectiva hacia otros seres, hacia la comunidad, así como la diferenciación con los afines que se evocan en la danza. Se desarrolla también una capacidad sumamente importante, esto es, la de transitar alternamente entre los polos de cohesión e individualidad, o diferencia e identidad. Como vimos en el caso de la danza del sol, cuando el hombre tiene el "cuerpo perfecto" - o el punto de vista humano lo suficientemente desarrollado- pareciera ser capaz de ser el espejo-otro de otro hombre sin dejar de ser él mismo. Él ha desarrollado la capacidad de repetir y es aquí donde debemos recordar que, para los Xavante, es el ciclo de repetición de los nombres de los grupos de edad lo que da la apariencia de continuidad en el tiempo. Por otra parte, vimos que esta etapa de transformación ontológica también es una lucha por ser merecedor del peso del nombre y del peso físico: el manejo del peso corporal es parte del proceso de diferenciación de la perspectiva humana. No parece haber una contraposición, como sí en otras ontologías occidentales, entre lo ligero y lo pesado, sino una integración dinámica entre ambos que puede apreciarse en el balance que consigue el danzante al moverse ritmicamente y luchar al mismo tiempo. Uno de los puntos que tocamos rápidamente en el análisis merece ahora ser resaltado. Como menciona Cristóvão Paridzané, el pop ’wara, como evocación de lo sagrado, 
no solo da sentido y vida a las danzas y cantos, sino que también está hecho para sufrir (APSIRE, 2014, 4m20s-4m40s). Las experiencias de dolor y vulnerabilidad humana son características de esta transformación ontológica: el ser que demostrará ser merecedor del punto de vista humano es un ser plenamente sintiente, un ser que escucha, siente la experiencia de cohesión y comunidad, observa, piensa y habla cuando debe hacerlo. La noción del cuándo también pareciera trabajarse en esta misma etapa de transición; pero, sin duda, lo visto pareciera sugerirnos que la conexión entre el dolor y la alteridad es inevitable. Es parte de vivir; se ha de estar preparado interna y externamente para ello. Por otra parte, ser una persona plena es solo el inicio del camino que ha de seguir el Xavante, quien pronto se incorporará a los asuntos políticos y sociales de la comunidad. Más aún, la danza -sin pretensión de exclusividad- pareciera aperturar esa instancia que permite que, en este camino, se reflexione no solo sobre la presencia del Otro afín, sino también de la supernaturaleza a la que refiere Viveiros de Castro (2015) o, en otras palabras, de la relación entre los vivos y los muertos. 


\section{Referencias bibliográficas}

APSIRE. (2014, 4 de Noviembre). Xavante Hö. Youtube. https://www.youtube.com/ watch?v=zl_twtT9MYw

Barcelos, A. (2006). “«Enfermedad de indio»: sobre el principio patogénico de la alteridad y los modos de transformación en una cosmología amazónica". Anthropológica, 25(24), 77106.

Bardet, M. (2012). Pensar con mover. Un encuentro entre danza y filosofía. Cactus.

Bell, C. (2009). Ritual Theory, Ritual Practice. Oxford.

Citro, S. (2012). "Cuando escribimos y bailamos: Genealogías y propuestas teórico metodológicas para una antropología de y desde las danzas". Cuerpos en movimiento: antropología de y desde las danzas. Biblos.

Costa, G. (2016). Xavante: Memória, Cultura, Resistência. Youtube. https://www.youtube. com/watch?v=GxH-Afqx1vY

Eliade, M. (2000). El mito del eterno retorno. Alianza Editorial.

Fernandes, E. (2010). “Do Tsihuri Ao Wardazu: O que as ideologias Xavante de concepção, substáncia e formação da pessoa nos dizem sobre o estatuto ontológico do outro?”. Horizontes Antropológicos. 34(16), 453-477.

Franco, R. \& Huertas, A. (2018). "Medios de comunicación e identidad Auwẽ-Xavante: Mito, Ritual y Política en el Brasil Central”. Anuario Electrónico de Estudios en Comunicación Social "Disertaciones", 11(2), 66-85.

Graham, L. (1995). "Sounds of Time, The Time of Sounds". Performing Dreams: Discourses of Immortality Among the Xavante of Central Brazil. University of Texas Press.

Graham, L. (2019). “A’ãma Mréme: A Playful Window into Auwẽ-Xavante Language, Cognition, and Social Organization”. Journal of Linguistic Anthropology, 29(2), 213-220.

Lopes da Silva, A. (1989). "Social Practice and Ontology in Akwe-Xavante Naming and Myth". Ethnology, 28(4), 331-341.

Martínez, I. (2007). "Eduardo Viveiros de Castro: De imaginación, traducción y traición”. An. Antrop. 41(2), 239-262.

Tserewahú, D. (1999, 16 de Abril). Wapté Mnhõnõ: Iniciação do Jovem Xavante. Vimeo. https://vimeo.com/ondemand/iniciacaodojovemxavante?autoplay=1

Turner, V. (1988). El proceso ritual: estructura y antiestructura. Taurus.

Valéry, P. (1965). Degas, danse, dessin. Gallimard.

Van Gennep, A. (2008). Los ritos de paso. Alianza Editorial. 
Viveiros de Castro, E. (2015). The Relative Native: Essays on indigenous conceptual worlds. Hau Books.

Von Laban, R. (1987). El dominio del movimiento. Editorial Fundamentos.

Welch, J. (2010). "Hierarchy, symmetry and the Xavante spiritual life cycle". Horizontes Antropológicos, 34(16), 235-259. 